\title{
Eye Movements During Reading and Topic Scanning: \\ Effects of Word Frequency
}

Sarah J. White

Kayleigh L. Warrington

Victoria A. McGowan

Kevin B. Paterson

School of Psychology, University of Leicester

Keywords: reading, scanning, skimming, word frequency, ex-Gaussian

\section{Corresponding Author:}

Sarah J. White

School of Psychology, University of Leicester, Lancaster Road, Leicester, LE1 9HN s.j.white@le.ac.uk 


\begin{abstract}
The study examines the nature of eye movement control and word recognition during scanning for a specific topic, compared to reading for comprehension. Experimental trials included a manipulation of word frequency: the critical word was frequent (and orthographically familiar) or infrequent (two conditions: orthographically familiar, orthographically unfamiliar). First-pass reading times showed effects of word frequency for both reading and scanning, with no interactions between word characteristics and task. Therefore, in contrast to the task of searching for a single specific word (Rayner \& Fischer, 1996), there are immediate and localised influences of lexical processing when scanning for a specific topic, indicating that early word recognition processes are similar during reading and topic scanning. In contrast, there were interactions for later measures, with larger effects of word frequency during reading than scanning, indicating that reading goals can modulate later processes such as the integration of words into sentence context. Additional analyses of the distribution of first-pass single fixation durations indicate that first-pass fixations of all durations were shortened during scanning compared to reading, and reading for comprehension produced a larger subset of longer first-pass fixations compared to scanning. Implications for the nature of word recognition and eye movement control are discussed.
\end{abstract}


Introduction

Many empirical studies (for a review see Rayner, 2009) and several sophisticated computational models (e.g. Engbert, Longtin, \& Kliegl, 2002; Reichle, Pollatsek, Fisher, \& Rayner, 1998) now provide excellent accounts of the mechanisms underlying eye movement behaviour during reading for comprehension. However a substantial proportion of everyday reading behaviour entails quickly looking through text to identify relevant information (Masson, 1982). Very little work has been undertaken into the mechanisms underlying such scanning behaviour. Research into the processes involved in scanning is clearly important in order to develop a broader understanding of the processes involved in word recognition and eye movement control. Critically, this work also enables us to further examine how the co-ordination of very different processes (linguistic processing and eye movement control) may be modulated by task demands or goals. We begin by outlining the type of scanning examined here and the processes that may be involved in this reading behaviour. We then highlight the importance of examining the nature of lexical processing for different types of reading behaviour and review previous studies that have manipulated task and word frequency. Finally we explore how the distribution of fixation durations can provide insights into the mechanisms underlying eye movement control during scanning for a topic and reading for comprehension.

\section{Topic scanning}

Scanning involves quickly looking through text to identify relevant information. In the present study we focus on scanning for a clearly defined topic. For brevity we will refer to this as "topic scanning", distinguishing it from other types of scanning such as scanning for features such as letters (Vitu, O’Regan, Inhoff, \& Topolski, 1995) or specific words (Rayner \& Fischer, 1996). Topic scanning might also be characterised as skimming for specific information. Previous studies have examined skimming by giving instructions such as "read as fast as possible" (Just \& Carpenter, 
1987; Laycock, 1955; Masson, 1982) or by giving participants a limited time to read the text (Duggan \& Payne, 2009; Masson, 1982, 1983). However the skimming behaviour that occurs as a result of time constraints may be different to that when specifically skimming for content relevant to a topic. Therefore, we use the phrase "topic scanning" to differentiate this task from other types of skimming or scanning.

Research on perspective effects provides insights into how relevant and irrelevant text might be processed. In contrast to topic scanning, studies of perspective effects employ broader definitions of relevance, for example, reading a passage from the perspective of a burglar or a homebuyer (Pichert \& Anderson, 1977), and these studies generally require participants to read at their own pace (e.g. Kaakinen, Hyönä, \& Keenan, 2002; though see Masson, 1982). Critically, the reading goals set the "standards of coherence" that form the criteria for comprehension (van den Broek, Lorch, Linderholm, \& Gustafson, 2001; van den Broek, Risden, \& Husebye-Hartmann, 1995). The aim may be to develop high standards of coherence for text relevant to a topic, whereas only superficial representations may be created for irrelevant text (Kaakinen \& Hyönä, 2008). The reading goals that motivate topic scanning may also be characterised as setting standards of coherence for relevant and irrelevant text.

For topic scanning, text may first be skimmed to extract the gist (Duggan \& Payne, 2009; Just \& Carpenter, 1987), characterised by eye movement behaviour such as few fixations and high skipping rates (Just \& Carpenter, 1987). The gist may then be used to assess the relevance of the text to the topic. If the text is deemed to be irrelevant, a low standard of coherence may be applied, such that any attempt to integrate the words within the text may be halted. Consequently, scanning of irrelevant text may produce very little behaviour indicative of higher level processing of the text, such as re-inspections of the text in the form of regressions back or re-reading.

Similar to semantic priming (Neely, 1977), the reading goals may raise activation for words associated with the semantic representation of the topic. In the framework suggested by Kaakinen 
and Hyönä (2008), a control mechanism (the central executive) keeps relevant elements in the reader's knowledge base activated, so that processing of relevant words in the text is facilitated. Once the text is deemed to be relevant, reading behaviour switches from scanning to reading for comprehension (Simola, Salojärvi, \& Kojo, 2008). We will refer to the reading behaviour that occurs for the relevant text as "topic comprehension". Note that the nature of the allocation of attention within the text may also change once the text becomes relevant (Kaakinen \& Hyönä, 2014).

Understanding how reading mechanisms are modulated by reading goals for speed, levels of comprehension required, and types of information sought within the text, is vital to developing a comprehensive theoretical account of the processes underlying reading. In particular, such work has the potential to provide key insights into the flexibility of the interactions between very different cognitive processes (eye movement control, attention, linguistic processing) within a complex skill. Some suggestions have been made for how mechanisms within models of eye movement control during reading might adapt to different reading tasks (Reilly \& Radach, 2006). However the models generally focus on accounting for reading for comprehension (Reichle, Rayner, \& Pollatsek, 2003), and none make specific predictions for reading behaviour during topic scanning. Very many aspects of the models may be modulated by reading goals, and we do not attempt to cover all of these in this manuscript. Instead, we focus on two issues that are particularly pertinent to understanding the mechanisms underlying eye movement control during reading: effects of lexical processing, and the effect of reading strategy on the distribution of fixation durations. In the following sections we outline the broad theoretical significance of these two issues. We then discuss more specifically in the General Discussion how the models might account for the findings.

\section{Word frequency effects across tasks}

Word frequency is measured by how often words occur in the language. Words with higher frequency are typically processed more quickly and accurately than words with lower frequency. The 
size of the word frequency effect has been shown to vary with task and the nature of the dependent variable. For example there are larger word frequency effects for response times in lexical decision than both naming times (Forster \& Chambers, 1973) and gaze durations during sentence reading (Kuperman, Drieghe, Keuleers, \& Brysbaert, 2013; Schilling, Rayner, \& Chumbley, 1998). By examining effects of word frequency across a range of reading goals we can gain insights into the extent to which different reading behaviours involve processing at a lexical level, and identify flexibility in the nature of lexical processing and how it affects behaviour. Such work is central to developing a theoretical understanding of how reading goals affect the processes involved in reading. The present study examines word frequency effects on eye movement behaviour during topic scanning, testing whether lexical processing occurs during topic scanning and comparing the size and time course of the effects to those during reading for comprehension.

Many studies have shown that eye movements during reading for comprehension are sensitive to differences in word frequency (Inhoff \& Rayner, 1986). These frequency effects have been shown to hold even when words disappear 60ms after initial fixation (Rayner, Liversedge, White, \& Vergilino-Perez, 2003), and they have been shown to hold for both short and long fixation durations (Staub, White, Drieghe, Hollway, \& Rayner, 2010; Reingold, Reichle, Glaholt, \& Sheridan, 2012). Together these studies provide strong evidence for direct cognitive control of eye movements during reading for comprehension. However other studies indicate that word frequency effects are smaller or absent when comprehension is less engaged, and that there are larger effects for more careful reading approaches.

Rayner and Fischer (1996) and Rayner and Raney (1996) showed that when readers were searching for a specific target word (in sentences and passages respectively), there were no frequency effects for other words within the text (see also Dampuré, Ros, Rouet, \& Vibert, 2012). These results indicate that when searching for specific words, the lexical characteristics of words in the text may not be processed. Instead, target words may be identified with a visual form matching 
strategy. Word frequency effects have also been shown to be reduced during mindless reading of text (Reichle, Reineberg \& Schooler, 2010; Schad, Nuthmann, \& Engbert, 2012). Mindless reading occurs spontaneously due to mind wandering and involves movement of the eyes through the text in the absence of comprehension. Together the studies of search and mindless reading of text indicate that when comprehension processes are less engaged, readers may not be processing the lexical characteristics of words to the same extent as when reading for comprehension.

In contrast, other studies have indicated that word frequency effects may be larger as a result of more careful reading. Radach, Huestegge, and Reilly (2008) showed a numerical trend for larger frequency effects when participants were given comprehension questions, compared to word verification questions, perhaps due to more careful reading in the comprehension testing condition. Just and Carpenter (1987) reported immediate effects of word frequency during rapid (speed/skim) reading, but indicated that the frequency effects were larger during normal reading (though only descriptive data were provided). Whitford and Titone (2014) also presented evidence to indicate that readers with higher comprehension scores (who perhaps were reading more carefully) showed larger word frequency effects than readers with lower comprehension scores. In general, these studies indicate that word frequency effects may be larger when reading more carefully. Similarly, proofreading may also be considered to be an especially careful form of reading, and word frequency effects have also been shown to be larger during proof-reading than reading for comprehension (Kaakinen \& Hyönä, 2010; Schotter, Bicknell, Howard, Levy, \& Rayner, 2014).

The studies discussed above indicate that word frequency effects are smaller when comprehension is less engaged and when reading behaviour is less careful. Word frequency effects during scanning for a topic have not previously been examined. However studies have shown that word frequency modulates eye movement behaviour when reading lists to identify words within the categories of clothing (Schroyens Vitu, Brysbaert, \& d'Ydewalle, 1999) or animals (Murray \& Forster, 2008). The word frequency effects in these tasks indicate that words within lists are 
processed to a lexical level when the task is to identify words within a category. If the nature of word processing and eye movement control is similar in the word list task and for topic scanning, then word frequency effects should also occur during topic scanning.

If word frequency effects do occur during topic scanning then some of the mechanisms that have been proposed to account for lexical influences on eye movements during reading for comprehension (e.g. Engbert et al., 2002; Reichle et al., 1998) may also be involved in topic scanning. In particular, if there are additive effects of task and target type (word frequency) then this would indicate that the same lexical processes may be employed in both tasks. However lower standards of coherence for topic scanning may result in more superficial processing of irrelevant text, such that lexical influences on eye movement behaviour may be smaller than during reading for comprehension. That is, there would be an interaction between task and target type, such that effects of word frequency were larger during reading than during topic scanning. Such interactive effects would indicate flexibility in the nature of the reading mechanisms as a function of reading goals.

Interestingly, another possibility is that some aspects of word processing may be the same for both topic scanning and reading (such as lexical access), while other aspects (such as post-lexical processing) may differ. Both lexical and post-lexical factors have been shown to influence both firstpass (fixations on a word before leaving or moving to the right of it) and later measures (incorporating re-reading) during reading for comprehension (for a review see Staub \& Rayner, 2007). However the speed of a cognitive process can affect when eye movement behaviour is modulated (Rayner \& Pollatsek, 1987). Furthermore, regressions back in the text can be triggered by processing associated with post-lexical integration of words into sentence context (Reichle, Warren, \& McConnell, 2009). It could be that early lexical processes that enable the reader to identify if the text is relevant produce similar patterns of eye movement behaviour during topic scanning and reading, for example, in first-pass measures. Such additive effects for first-pass measures would indicate that the mechanisms proposed to account for lexical influences on eye movements during 
reading for comprehension (e.g. Engbert et al., 2002; Reichle et al., 1998) may also hold during initial processing of words during topic scanning. However, lower standards of coherence during topic scanning may produce much less integration of words into sentence context compared to reading for comprehension. Consequently, word frequency may have a smaller effect on behaviour associated with integration of words into context, in particular regressions and re-reading. Therefore measures linked to re-reading (such as total time) may show interactive effects of task and target type. Such interactive effects for later measures may indicate that mechanisms involved in postlexical integration (Reichle, Warren et al., 2009) are modulated by reading goals.

Together the studies of word frequency effects across tasks support the notion that reading processes and behaviour adapt according to reading goals, reflecting flexibility in the cognitive systems underlying reading (Bicknell \& Levy, 2010; Lewis, Shvartsman, \& Singh, 2013; McConkie, Rayner, \& Wilson, 1973; Schotter et al., 2014). These issues are further examined in the present study in relation to topic scanning. The General Discussion includes more detailed consideration of how models of eye movement control might account for such flexibility. However note that some tasks, such as search, proof-reading and list reading, may incorporate task-specific mechanisms. For example, a model of search (employing visual form matching) may be more appropriate to account for the task of searching for specific words in text than a model of reading.

\section{Using ex-Gaussian analyses to further explore eye movement control during topic scanning}

In addition to examining the nature of lexical processing during topic scanning, we also address the broader issue of how reading goals can modulate the duration of fixations. In particular, we examine whether the mechanisms that produce longer single (first-pass) fixation durations during reading compared to topic scanning affect fixations of all durations and/or a subset of longer fixations. We do this by fitting the fixation duration distributions to the ex-Gaussian distribution (Balota \& Yap, 2011; Ratcliff, 1979; Staub et al., 2010). The ex-Gaussian distribution is the 
convolution of a normal (Gaussian) and an exponential distribution. Three parameters characterise the distribution: $\mathrm{mu}(\mu)$ represents the mean of the normal component; sigma $(\sigma)$ represents the standard deviation of the normal component; and tau $(\tau)$ reflects the mean and standard deviation of the exponential component. A number of studies have examined how a range of word characteristics (stimulus quality, word frequency, predictability, lexical ambiguity) affect the distribution of fixation durations during reading for comprehension (Reingold et al., 2012; Sheridan \& Reingold, 2012a, 2012b; Staub et al., 2010; Staub, 2011; White \& Staub, 2012). In the present study the ex-Gaussian analyses enable a test of whether fixation durations for topic scanning and reading for comprehension differ for fixations of all durations (shift in the distribution, shown by a difference in $\mu$ ), and/or if there is a particular effect on a subset of long fixations (increase in the weight of the right tail of the distribution, shown by a difference in $\tau$ ).

Note that the ex-Gaussian distributions are fitted for each participant and each condition, and the parameter values are then compared across the conditions. Consequently the fitting procedure requires a large number of observations per participant per condition. The comparison of the topic scanning and reading conditions is therefore based on fixation durations across the sentence, for which there are plenty of cases. Note that other distributions may also provide a good fit (Van Zandt, 2000), but that the ex-Gaussian distribution is used here, as a descriptive model (Matzke \& Wagenmakers, 2009), because it enables a test of whether task affects fixations of all durations and/or a subset of longer fixations.

Critically, the nature of the distribution of fixation durations has key implications for understanding the eye movement control mechanisms associated with different reading strategies. If fixations of all durations are shorter during topic scanning compared to reading, such that there is a shift in the entire distribution of fixation durations, then this would indicate that eye movement programming is modulated by the scanning strategy for all/most fixations. Such an effect of strategy on fixations of all durations could be due to an effect of either, or both, oculomotor or linguistic 
mechanisms. That is, the timing within oculomotor mechanisms, or lexical processing mechanisms, may be speeded during topic scanning, such that fixations of all durations are shortened during topic scanning compared to reading for comprehension. The results of the present study will not distinguish between these very different oculomotor and lexical accounts, but critically the study will reveal if differences in fixation durations might be explained by mechanisms that affect fixations of all durations.

An alternative possibility is that only a subset of longer fixations may be modulated by task, as shown by Luke and Henderson (2013) for fixation durations during "mindless reading” of nonlinguistic stimuli compared to normal reading for comprehension. If shortened average fixation durations during topic scanning are explained by a larger subset of long fixation durations during reading for comprehension, then differences between the two tasks may be due to a subset of fixations for which processing of words during reading for comprehension is particularly effortful. Finally, it could be that strategy affects the duration of all fixations, as well as having a particular influence on a subset of long fixation durations. In the General Discussion we consider further how models of eye movement control during reading might account for how reading strategy affects the duration of all or a subset of fixations.

\section{Experiment}

In order to enable careful control of the experimental stimuli, and also to enable very accurate eye position recording to precisely localise what is processed when, the present study employed single sentence stimuli (rather than longer passages of text). Participants scanned the sentences quickly to identify those relevant to the topic of clothing. The topic of clothing was selected given that it has been employed in previous studies (e.g. Schroyens et al., 1999), and as a topic for which all readers should have high prior knowledge, such that relevant text should be easily identified (Kaakinen \& Hyönä, 2007). In the topic scanning task, a question was presented only after a relevant 
sentence, whereas in the reading for comprehension task, a question was presented after every sentence. Reading behaviour can be modulated by the nature and frequency of questions following the text (McConkie \& Rayner, 1974; McConkie et al., 1973; Wotschack, \& Kliegl, 2013), hence presenting a question after every sentence ensured a strategy of reading for comprehension. Nevertheless, the questions were quite straightforward and often used similar wording to that in the sentences (as noted for the easy questions in Wotschack \& Kliegl's study). Therefore although reading for comprehension was encouraged by the frequency of the questions, extremely careful reading was not required to complete the reading task.

The experimental items were based on those used by White (2008) (with a few adaptations, see Method). White's materials not only include a manipulation of word frequency, but also control for, and provide a further test of, orthographic familiarity. There were three conditions: frequent and orthographically familiar (e.g. town); infrequent and orthographically familiar (e.g. cove); infrequent and orthographically unfamiliar (e.g. quay). Differences between the first two conditions represent an effect of word frequency with orthographic familiarity controlled, such that any difference between these two conditions should reflect an influence of lexical processing. In contrast, any differences between the two infrequent conditions may reflect an influence at the level of sub-lexical orthography. In the original study, involving standard reading for comprehension, there were clear effects of word frequency in both first-pass eye movement measures for the critical word and total time on the critical word. In contrast there were only smaller first-pass effects of orthographic familiarity. The present study provides an opportunity to test whether the same pattern holds during topic scanning as well as reading for comprehension. Note that we were especially interested to retain the manipulation of orthographic familiarity given that, due to the shorter time available for text processing, it could be that sub-lexical processing of words may exert a greater influence on eye movement behaviour during topic scanning than reading for comprehension.

The study also examines to what extent first-pass effects of target type are localised to eye 
fixations on the critical word. Note that analysing fixations prior to the critical word provides a test of parafoveal-on-foveal effects (Kennedy, 2000). If the characteristics of the critical word influence fixation durations prior to the critical word during topic scanning, this could indicate that multiple words might be processed in parallel when scanning text. In contrast, if word frequency effects are localised to measures associated with processing during and after fixating the critical word, this would be consistent with attention being allocated serially to each word (Reichle, Liversedge, Pollatsek, \& Rayner, 2009).

Method

Participants. Twenty-four individuals from the University of Leicester community participated; they were given $£ 6$ to compensate for their time. All participants were native English speakers, aged between eighteen and thirty years, with normal or corrected-to-normal vision and had no history of dyslexia. Participants were naïve in relation to the purpose of the experiment.

Apparatus. Eye-movements were recorded using an Eye-Link 1000 eye tracker (SR Research Ltd.). Pupil location was sampled at a rate of $1000 \mathrm{~Hz}$. Viewing was binocular though only movements of the right eye were recorded. The sentences were presented on a View-Sonic P227fb monitor with a refresh rate of $7 \mathrm{~ms}(150 \mathrm{~Hz})$. Viewing distance were $80 \mathrm{~cm}, 3.3$ characters extended across approximately one degree of visual angle.

Materials \& Design. The design was 2 (task: reading, topic scanning) x 3 (critical word: frequent orthographically familiar, infrequent orthographically familiar, infrequent orthographically unfamiliar), within participants and items. Stimuli were presented in two blocks, a reading block and a topic scanning block. Each block included 54 experimental sentences plus ten sentences relevant to the topic of clothing. The experimental items were largely based on those of White (2008), three items were deleted and six were adjusted in order that none referred to the topic of clothing and that the critical words conformed to the experimental conditions (see below). The clothing items were 
written to resemble the experimental items and the clothing-relevant text could appear at any point within the sentence. Example items are shown in Table 1.

\section{Insert Table 1 about here}

Both the experimental and clothing items were presented as single lines of text (maximum 80 characters) in Courier font in black on a light grey background. The experimental items consisted of 36 neutral initial sentence frames, with three versions of each item corresponding to each of the three critical word conditions. As in White (2008), participants read all three versions, resulting in 108 experimental sentences. The six experimental conditions were manipulated within participants and items for the experimental items, and the clothing stimuli were also manipulated within participants and items across the reading and topic scanning conditions. Each participant completed both reading and topic scanning blocks, and the order of the blocks was counterbalanced across participants. Each block was preceded by fifteen practice sentences. In the reading condition all sentences were followed by a comprehension question. In the topic scanning condition, only clothing related items were followed by a question.

For the experimental items, the critical words (word n) were four or five letters long and the words immediately preceding the critical word (word n-1) were four to six letters long. The sentence completion norms for 12 participants reported by White (2008) were re-examined. Just as in the original study, only two completions $(0.4 \%)$ were correct, hence none of the critical words were predictable from the sentence context. Word frequencies and n-gram frequencies were re-calculated for the revised stimulus set using the HAL corpus (Lund \& Burgess, 1996). Counts were downloaded from the English Lexicon Project database (Balota et al., 2007, downloaded 9/7/13) and are reported here as log frequencies. For the orthographically familiar words, the frequent words had higher word frequencies $(M=11.35, S E=0.13)$ than the infrequent words $(M=6.74, \mathrm{SE}=0.16), t(70)=22.27, p$ $<.001$. For the infrequent words, there was no significant difference ${ }^{1}$ in word frequency between the orthographically unfamiliar $(M=6.52, S E=0.20)$ and familiar conditions $(t<1)$. 
See White (2008) for details of the orthographic familiarity manipulation and the original calculations based on the CELEX corpus (Baayen, Piepenbrock, \& Gulikers, 1995). Trigram frequencies were re-calculated for the revised 36 items using counts from the HAL corpus to verify that the manipulations of familiarity held for the revised stimulus set. Both type frequency (the number of words that contain a particular letter sequence) and token frequency (the sum of the frequencies of words that contain a particular letter sequence) were calculated, both specific to position and non-position specific. For all of the measures for the infrequent conditions, the orthographically unfamiliar words had significantly lower counts than the orthographically familiar words $(t \mathrm{~s}>6.9, \mathrm{ps}<.001)$. Also, for all of the measures for the orthographically familiar words, there were no differences in trigram frequencies between the frequent and infrequent word conditions $(t \mathrm{~s}<1.5, p \mathrm{~s}>.15)$.

Procedure. Participants were screened for visual acuity at the viewing distance $(80 \mathrm{~cm})$ using an ETDRS chart (Ferris \& Bailey, 1996). Participants' visual acuity was 20/25 or greater. Participants received separate instructions for each block of trials. In the reading block, participants were instructed "you should read all of the sentences carefully. You will be asked a comprehension question after every sentence". In the topic scanning block participants were instructed "you should scan the sentences quickly to identify those that are relevant to the topic of clothing. If the sentence is not relevant to the topic, quickly press a button to move on, you will not receive questions on these irrelevant sentences. However if the sentence is relevant to the topic of clothing then ensure you read it carefully as there will be a comprehension question after every sentence that relates to the clothing topic".

A chinrest and forehead rest minimized head movements. The eye tracker was calibrated using a three-point horizontal calibration. The calibration was checked centrally before every trial and at the three calibration positions every three trials, ensuring that calibration accuracy was $<0.3$ degrees at each of the three calibration positions. Recalibrations were undertaken if necessary. 
Participants had to accurately fixate on a fixation cross at the position of the start of the line of text before each item was presented. Participants pressed a button to indicate when they had finished reading/scanning each sentence. They also pressed buttons to respond "yes" or "no" to question statements where appropriate.

Analyses. Fixations shorter than $80 \mathrm{~ms}$ or longer than $1,200 \mathrm{~ms}$ were discarded $(2.4 \%$ of fixations). The analyses include global measures, incorporating eye movement behaviour across the sentence, and local measures, examining the effects of word frequency and orthographic familiarity for the experimental items. The ex-Gaussian analyses of the distribution of fixation durations were restricted to single first-pass fixations on words four to seven letters long, excluding fixations on the first and last words within each sentence. Single fixations with these criteria were selected in order that the findings may specifically be applied to first-pass processing of words in the text. Other types of fixations (e.g. refixations on words, regressions, re-reading fixations) and fixations at other positions within the sentence (Kuperman, Dambacher, Nuthmann, \& Kliegl, 2010) may show different patterns. The analyses were restricted to medium length words as these are perhaps most likely to receive single fixation durations in both the topic scanning and reading for comprehension conditions. The QMPE software (Cousineau, Brown, \& Heathcote, 2004; Heathcote, Brown, \& Mewhort, 2002) was employed, using quantile maximum likelihood estimation to determine the best fitting parameters. As in White and Staub (2012), separate fits were produced for each participant and each condition, and the maximum number of quantiles were used in the fitting procedures (each data point is effectively in a separate quantile bin) (see Heathcote et al., 2002). Importantly, the restriction to single fixations yielded plenty of cases per participant per condition (reading: $M=219$, $S E=6.2$; scanning: $M=178, S E=7.1)$.

\section{Results and Discussion}

For the experimental items in the reading task, comprehension accuracy was high $(M=97 \%)$ with all participants scoring $93 \%$ or higher. Comprehension accuracy for the clothing related items 
was high in both the reading $(M=99 \%)$ and topic scanning $(M=96 \%)$ tasks, with all participants scoring at least $80 \%$ in each condition. The high level of accuracy in the topic scanning task indicates that participants successfully comprehended the relevant sentences, despite the overall shorter reading times in this task (see below).

Global analyses of eye movement behaviour

Measures of eye movement behaviour across the sentence are presented separately for the irrelevant and relevant items in order to examine eye movement behaviour during topic scanning and topic comprehension. In addition, ex-Gaussian analyses are reported to examine the effect of topic scanning on the distribution of single fixation durations. For all of the global measures, paired sample $t$-tests were undertaken. For the measures of eye movement behaviour across the sentence, $t$ tests were undertaken across participants $\left(t_{1}\right)$ and items $\left(t_{2}\right)$ for each measure. First-pass summed reading time is the sum of first-pass fixations (gaze durations) for each of the words within the sentence. Re-reading time is the sum of all fixations on each of the words after first-pass (following regressions back in the text).

Global results for reading and topic scanning: Eye movement behaviour for topic scanning is examined by analysis of the experimental (topic-irrelevant) items. Mean measures and $t$-values are shown in Table 2. There were significant effects of task for all measures of global eye movement behaviour across the sentence. Reading times were longer when reading for comprehension compared to topic scanning, shown by both first-pass summed reading time and re-reading time. Consistent with this pattern, there were more first-pass and re-reading fixations during reading than topic scanning and average fixation durations were longer. Table 2 also shows the mean progressive saccade length (that is, the length of rightward going saccades). Progressive saccade lengths were shorter ${ }^{2}$ during reading compared to topic scanning. Overall the results indicate that reading for comprehension requires more and longer fixations to sample text than topic scanning. 
Insert Table 2 about here.

Ex-Gaussian analyses were undertaken to further examine how the difference in mean fixation durations can be accounted for by differences in the distributions. The QMPE software was used to generate the three ex-Gaussian parameters outlined in the Introduction: $\mu$ represents the mean of the normal component; $\sigma$ represents the standard deviation of the normal component; and $\tau$ reflects the mean and standard deviation of the exponential component. Paired sample $t$-tests were undertaken for each of the three parameters, comparing the parameters for each participant across the two conditions. There were significant effects of task for both the $\mu$ and $\tau$ parameters, but not $\sigma$. The differences in mean parameter values indicate that the distribution of single fixation durations for reading for comprehension was shifted to the right, and with greater weight in the slow tail of the distribution, compared to that for topic scanning. That is, shorter single fixation durations during topic scanning compared to reading for comprehension are accounted for both by a shortening of fixations of all durations, and by a smaller proportion of long fixation durations in the topic scanning compared to the reading task.

The pattern of differences indicated by the ex-Gaussian parameters is supported by the vincentile plot (Ratcliff, 1979; Vincent, 1912) shown in the Figure. Vincentile plots are created by dividing each participant's observations into ten bins, such that the shortest $10 \%$ of observations are in the first bin, the next shortest $10 \%$ in the second bin etc. The Figure shows the mean and standard error of the observed participant means for each of the conditions for each of the bins. The separation of the curves reflects the shift in the distribution, and the increase in separation for the higher vincentiles reflects the difference in the exponential distribution. Note that the Figure also shows predicted vincentiles, generated by simulating ex-Gaussian distributions based on the mean of the best-fitting parameters and 50,000 random samples. Importantly, the predicted and observed values are very similar, indicating that the best fitting parameters accurately reflect the observed distributions. Both the ex-Gaussian parameters and the descriptive data are consistent with single 
fixation durations across the full range of fixation durations being modulated by task, as well as task having a particular influence on the frequency of long fixations.

Insert Figure about here.

Global results for reading and topic comprehension: For the clothing related items, participants read for comprehension in the reading task, but in the topic scanning task they first had to scan for the relevant topic, and then read more carefully in preparation for the question. The clothing related content could appear at any position in the sentence, so it was not feasible to analyse behaviour before and after reaching the relevant content. Therefore behaviour for "topic comprehension" incorporates both initial scanning and subsequent behaviour involved in reading for comprehension. Mean measures and $t$-values are shown in Table 3. There was no effect of task for re-reading time, the number of re-reading fixations, or average fixation duration. However first-pass summed reading times were significantly shorter (also significantly fewer first-pass fixations) for topic comprehension compared to reading. Similar to the results for topic scanning, progressive saccades were significantly shorter during reading compared to topic comprehension. Importantly, although re-reading behaviour was similar for reading and topic comprehension, first-pass reading behaviour was reduced during topic comprehension, such that overall reading times were shorter during topic comprehension than reading, despite the need to read these relevant sentences carefully. The comprehension scores for the questions related to the relevant sentences in the scanning task were high, but as the response accuracies approached ceiling for both topic comprehension and reading for comprehension, it is difficult to conclude whether the overall shorter processing times for topic comprehension might have affected deeper levels of comprehension.

Insert Table 3 about here.

Summary of global analyses: The global measures provide key insights into the general pattern of eye movement behaviour that occurs during topic scanning and topic comprehension compared to behaviour during reading for comprehension. The shorter reading times, fewer fixations 
and shorter fixation durations shown during topic scanning compared to reading is in line with topic scanning producing skim reading behaviour. Distributional analyses further indicate that single firstpass fixations of all durations are modulated by reading strategy, and that reading for comprehension has a particular influence on a subset of long fixations. The implications of these findings for the mechanisms underlying eye movement control during reading and topic scanning are considered in the General Discussion.

Reading times were numerically longer during topic comprehension compared to topic scanning, in line with previous findings of longer reading times on relevant compared to irrelevant text (Kaakinen et al., 2002). Interestingly, reading times were shorter during topic comprehension compared to reading for comprehension, indicating that the topic scanning task speeds text processing even when full comprehension is required. Furthermore, shorter first-pass reading times are not compensated for by longer subsequent re-reading times. It could be that the processing of relevant text during topic comprehension is facilitated by raised activation of relevant concepts (Kaakinen \& Hyönä, 2008).

Local analyses for reading and topic scanning

The local analyses reveal the nature of lexical processing during topic scanning by examining the effects of target type. Note that the local analyses exclude cases in which there were blinks on the critical word (1.9\% of cases). A series of 2 task (reading, topic scanning) X 3 target type (frequent, infrequent familiar, infrequent unfamiliar) repeated measures Analyses of Variance (ANOVA) were undertaken with participants $\left(F_{1}\right)$ and items $\left(F_{2}\right)$ as random factors. Analyses were corrected for sphericity where necessary. Bonferroni corrected pairwise comparisons were performed where appropriate. Critically, additive effects of task and target type indicate that word processing is similar across both reading and topic scanning. In contrast interactive effects indicate that word processing is modulated by reading strategy. Differences between the three levels of target type enable separate 
examination of effects of word frequency and orthographic familiarity. Crucially, a difference between the frequent and infrequent word orthographically familiar conditions represents an effect of word frequency. As orthographic familiarity is controlled, any word frequency effects reflect processing at a lexical level. In contrast, a difference between the two infrequent word conditions (orthographically familiar and orthographically unfamiliar conditions) may instead be explained by orthographic familiarity, that is, by processing at a sub-lexical level. Measures for the critical word are first presented, followed by analyses of word skipping and fixation durations before and after the critical word.

Critical word: Mean reading measures for the critical word are shown in Table 4 and ANOVA statistics are reported in Table 5. In order to examine initial processing of the critical word, first-fixation duration (the duration of the first fixation on the word on first-pass) and gaze duration (the sum of fixation durations on the word before leaving it on first-pass) were analysed. Both of these first-pass reading times were significantly longer during reading compared to topic scanning. Importantly there were significant effects of target type and no interactions between task and target type. There were significant effects of word frequency for both first fixation durations and gaze durations $(p s<.001)$. Critically, these results show that for both reading and topic scanning there are immediate effects of word frequency on fixation durations on the critical word, and the size of these effects is not modulated by task. Therefore, although reading times are shorter during topic scanning compared to reading, the lexical characteristics of words may have a similar initial influence on word recognition processes and eye movement behaviour when the words are first processed. Note that there were no significant effects of orthographic familiarity for either first fixation duration or gaze duration $(p s>.1)$. However in the reading task, both these measures were numerically longer for orthographically unfamiliar compared to familiar words, and the size of this difference is similar to that observed by White (2008). We also examined the proportion of regressions made out of the critical word on first-pass. There was no significant effect of task and no interaction between task 
and target type. There was a trend for a main effect of target type which was significant by items but not participants $(p=.057)$. Contrasts showed an effect of frequency $(p s<.05)$, but no effect of orthographic familiarity $(p s>.6)$.

Insert Tables $4 \& 5$ about here.

Similar to the first-pass reading time measures, total time (sum of fixation durations on the word) also showed main effects of target type and task, but importantly there was also a significant interaction. There were significant effects of word frequency on total times for both reading and topic scanning $(p s<.01)$. The effect of word frequency was larger for reading compared to topic scanning (69ms vs. $40 \mathrm{~ms}$ respectively), $t_{1}(23)=2.05, p=.05$. There were no significant effects of orthographic familiarity for either task ( $p s>.3$ ), but the interaction may also reflect the larger difference between the frequent and infrequent orthographically unfamiliar condition for reading (77ms) compared to topic scanning $(27 \mathrm{~ms}), t_{1}(23)=3.41, p<.01$.

To further explore the interactive pattern in total time, we examined the proportion of regressions made in to the critical word. Regressions in to the critical word also showed main effects of task and target type, and a trend towards a significant interaction $(p s<.1)$. However Luke and Henderson (2013) recently showed effects of word frequency on regressions in only for cases in which words were fixated during first-pass. Therefore we undertook a further analysis of regressions in, restricted to trials in which the critical word was fixated during first-pass. For these trials, similar to the measure for total time, there were significant main effects of both task and target type, and there was an interaction that was significant by participants though not by items $(p=.056)$.

Consistent with Luke and Henderson, for reading for comprehension there were more regressions in to the critical word when it was infrequent (orthographically familiar) compared to when it was frequent $(p s<.01)$. Critically, the frequency effect for regressions in was significantly larger for reading for comprehension compared to topic scanning, $t_{1}(23)=2.41, p<.05$. The greater likelihood of revisiting infrequent compared to frequent words during reading for comprehension no doubt 
increased total times, and therefore also accounts for the larger effect of word frequency on total times during reading for comprehension compared to topic scanning. Importantly, these results contrast with the additive effects of task and target type for first-pass measures. Together the results indicate that although initial lexical processing of words is similar for reading and topic scanning, later processing is modulated by task, such that lexical characteristics have a greater influence on later processing of words during reading for comprehension compared to topic scanning.

Also note that the difference in total times between the frequent and the infrequent orthographically unfamiliar condition was also significantly greater during reading than topic scanning ( $77 \mathrm{~ms}$ vs. $27 \mathrm{~ms}$ respectively, as detailed above). The mean reading times indicate that there was very little re-reading of the orthographically unfamiliar words during topic scanning. Compared to the orthographically familiar words, the orthographically unfamiliar words were less orthographically familiar, had fewer orthographic neighbours (White, 2008), and may even be less frequent than the infrequent orthographically familiar words (see Footnote 1). One or a combination of these factors could perhaps minimise later processing of these words during topic scanning. In the final section of the results we explore whether the characteristics of the critical word affect fixations just before and just after processing the critical word on first-pass.

Word skipping and fixation durations before and after the critical word: In order to more fully investigate the time-course of processing of the critical word, we report the probability of skipping the critical word, the fixation duration just before fixating the critical word, gaze durations on the previous word (n-1), and the fixation duration just after leaving the critical word on first-pass. Means are shown in Table 6 and ANOVA statistics are shown in Table 7.

Insert Tables 6 and 7 about here

For the proportion of cases in which the critical word was skipped on first-pass, there were significant main effects of task and target type and no interaction. Skipping rates were higher for topic scanning than reading, which is consistent with the global analyses showing fewer first-pass 
fixations and longer progressive saccades for scanning. Despite the main effect of target type, contrasts between levels of word type were not reliable across both participants and items. To further examine the effect of skipping on target type, an analysis was undertaken that was restricted to cases in which word n-1 was fixated on first-pass, hence providing a close preview of the critical word. For these cases with nearer launch sites, skipping probabilities were greater than for those including all launch sites for both reading and topic scanning. For cases in which word n-1 was fixated on firstpass, the ANOVA results showed the same pattern as for all of the cases with significant main effects of both target type and task and no interaction. For reading for comprehension, frequent words were skipped numerically more often than infrequent familiar words. Although this difference was not significant, the direction is consistent with previous findings (Rayner, Sereno, \& Raney, 1996; White, 2008). However the infrequent orthographically unfamiliar words were significantly less likely to be skipped than the frequent words $(p s<.01)$. As noted above, the effect for infrequent orthographically unfamiliar words could be driven by processing at a number of levels including word frequency, orthographic familiarity, or the number of neighbours. At the very least the results indicate that parafoveal processing of words, at least at the sub-lexical level and when there is a close parafoveal preview, can influence word skipping during both reading and topic scanning.

For reading behaviour prior to the critical word, we examined the fixation duration prior to fixating the critical word, and gaze duration on word n-1. Note that due to the longer saccade lengths and more distant launch sites during topic scanning (see Footnote 2) it was not possible to restrict analyses of fixation durations to those very close to the critical word, as has been done in previous studies (e.g. White, 2008). Gaze duration on n-1 and the fixation duration prior to fixating the critical word both showed main effects of task but neither showed any evidence of an effect of target type or an interaction. Therefore for both reading and topic scanning there was no evidence that the frequency or orthographic familiarity of the critical words influenced fixation durations prior to the critical word. That is, neither reading nor topic scanning showed any evidence of parafoveal-on- 
foveal effects, consistent with the notion of serial processing of words (Reichle, Liversedge et al., 2009).

We also examined the duration of the fixation after leaving the critical word on first-pass (spillover). There was a main effect of task and no interaction between target type and task. Fixations were numerically longer after leaving infrequent compared to frequent words but there was no significant main effect of target type $(p s>.1)$. Effects of word frequency on spillover have been shown to vary across studies, with some studies showing significantly longer fixation durations following infrequent compared to frequent words (e.g. Rayner \& Duffy, 1986) and others showing no difference (e.g. Henderson \& Ferreira, 1990). Critically, the absence of an interaction for spillover is consistent with the pattern for the first-pass reading time measures, indicating that the nature of the task did not modulate initial lexical processing of the critical word.

Summary of local analyses: The local analyses provide key insights into the nature of lexical processing during topic scanning. Although mean first-pass reading times were shorter during topic scanning, the effects of word frequency were the same across all first-pass measures. Furthermore, the effects of word frequency were localised to the critical word in both tasks. Together these findings indicate that initial lexical processing of words during topic scanning is similar to that during reading for comprehension, hence similar mechanisms may account for the effects in both tasks. By comparison, later measures showed interactive effects of task and word frequency, with larger effects of word frequency on total times and the proportion of regressions back to the critical word during reading for comprehension. Therefore, mechanisms that affect re-reading behaviour, such as post-lexical integration of words within the sentence, may differ across the tasks.

\section{General Discussion}

In the sections below we consider in more detail the implications of the results for the nature of word recognition and eye movement control during topic scanning. We first outline the 
implications for initial lexical processing of fixated words during topic scanning. A second section draws on evidence from the distribution of first-pass single fixation durations to explore the implications for the control of fixation durations. A third section considers how lexical characteristics of words might affect saccade timing (fixation durations) and targeting (word skipping). A fourth section explores the effect of reading strategy on later (re-reading) measures. A final section highlights issues for further research.

Initial lexical processing of fixated words during reading and topic scanning

The present study provides clear evidence that word frequency modulates first-pass reading times during topic scanning. Critically, these results demonstrate that topic scanning involves the processing of words at least at the lexical level, despite shorter overall reading times compared to reading for comprehension. These findings contrast with those of previous studies employing tasks that do not require full comprehension of text. In particular, they contrast starkly with studies showing word frequency has no effect on eye movement behaviour when searching for specific words in text (Rayner \& Fischer, 1996; Rayner \& Raney, 1996).

First-pass effects of word frequency were localised to the critical word and were of a similar magnitude for reading for comprehension and topic scanning, indicating that initial processing of words was similar across these tasks. By comparison, tasks, such as proof-reading, which induce particularly careful reading, produce larger frequency effects compared to reading for comprehension (Kaakinen \& Hyönä, 2010; Schotter et al., 2014). Overall, these differential effects of word frequency suggest considerable flexibility in the nature of the word identification processes involved in different reading behaviours.

Eye movement control during first-pass: The distribution of fixation durations

Global analyses of the distribution of fixation durations demonstrate that single first-pass 
fixations are shortened during topic scanning, due to a combination of a general shift in the distribution of fixation durations (affecting fixations of all durations) and a larger subset of long fixation durations during reading for comprehension. The effect for fixations of all durations indicates that scanning affects an eye movement control mechanism that shortens all/most first-pass fixations. This could be mediated by a general oculomotor mechanism that adjusts the average time at which saccades are triggered. For example, in the SWIFT model (Engbert, Nuthmann, Richter, \& Kliegl, 2005) saccade programming is triggered by a random timer. The average and range of times produced by this timer could be adjusted as a function of reading strategy. If the timer produced shorter times (across the full range of times) during scanning compared to during reading for comprehension, fixations of all durations would be affected. Alternatively, this effect might be explained by linguistic processes triggering saccades earlier. In the E-Z Reader model, saccade programming is triggered by completion of the first stage of word recognition $\left(\mathrm{L}_{1}\right)$ (Reichle, Warren et al., 2009). If the rate of lexical processing is increased during scanning, such that words are identified (and $\mathrm{L}_{1}$ completed) more quickly, this would shorten fixations of all durations. In the Glenmore model (Reilly \& Radach, 2006) effects of reading strategy might be accounted for by differences in the threshold for letter and word activation that affect the timing of saccade triggering.

The additional finding that the proportion of longer fixations is greater for reading for comprehension than topic scanning reveals an effect of reading task on a subset of longer fixations. As discussed above, one possibility is that fixation durations are determined by the timing of lexical processing, such as the $\mathrm{L}_{1}$ stage in E-Z Reader. Differences in the distribution of the timing of lexical processing, such as greater skew in this distribution for reading for comprehension, may be reflected in the distribution of fixation durations. Alternatively, this effect may be explained by Staub and Benatar's (2013) suggestion, that differences in $\tau$ reflect effects of processing disruption. Such disruption, related to either lexical or post-lexical processing, may be more likely during reading for comprehension than scanning. Some models of eye movement control specifically predict a 
particular influence of processing difficulty for longer fixations (Yang \& McConkie, 2001), and it could be that there is a greater effect of such difficulty during reading for comprehension than topic scanning. Another possibility is that post-lexical processing may be specifically linked to the subset of longer fixation durations. For example, in E-Z Reader the parameter that represents integration of words into higher level sentence representations (I) influences eye movement behaviour only when it fails, that is, only in a subset of cases. This integration failure may occur more often during reading for comprehension than scanning, and so produce a larger subset of longer fixation durations.

To summarise, differences in the distribution of first-pass fixation durations across reading tasks may be explained by processing at a range of levels, from basic oculomotor mechanisms, to lexical, and even post-lexical, processing. However the key finding is that fixations of all durations are modulated during scanning, hence the mechanism that produces shortened fixation durations during scanning affects all/most fixations.

\section{Eye movement control during first-pass: Effects of word frequency}

The present study shows similar effects of word frequency in first fixation durations for topic scanning and reading for comprehension. These results indicate that, despite shorter fixation durations for scanning, the influence of lexical processing on first fixation durations is similar. This might reflect differences in the rate of lexical processing across tasks, such that fixations are shortened during scanning, but the effect of lexical processing remains the same. Note that differences in the size of word frequency effects for other reading strategies might be explained by differential linguistic influences on the triggers for saccade programming. For example, lower thresholds for lexical activation affecting the timing of saccade triggering (Reilly \& Radach, 2006) may reduce the influence of word frequency on fixation durations for reading goals such as skimming under time pressure (Just \& Carpenter, 1987) or reading with minimal levels of comprehension (Radach et al., 2008). 
Although word frequency influenced first-pass reading times during both reading for comprehension and topic scanning, effects of orthographic familiarity (differences between the two infrequent conditions) were smaller in both tasks. For the reading task, there were no significant effects of orthographic familiarity, although there were numerically longer first-pass reading times (13ms for gaze duration) for orthographically unfamiliar compared to familiar words. Topic scanning showed no influence of orthographic familiarity on first-pass reading times. Importantly these results indicate that, in both tasks, sub-lexical orthographic characteristics of words have limited influence on word processing time. Effects of word frequency and the absence of effects of orthographic familiarity during scanning clearly indicate that it is the lexical processing of words that influences first-pass reading times. Furthermore, immediate effects of word frequency on first-pass fixations during topic scanning suggests cognitive factors are central to when the eyes move during scanning, just as for reading for comprehension (Rayner et al., 2003). However further work is needed to more fully reveal this influence.

Indeed, even though word frequency influences mean fixation durations similarly across tasks, the nature of this influence might differ. For example, word frequency might exert an influence early during fixations in topic scanning, influencing fixations of all durations and so producing a shift in the distribution, consistent with direct cognitive control for all fixations. Alternatively if word frequency exerts a later influence on only a subset of longer fixations, this would be consistent with a cognitive influence rather than direct control. Techniques such as ex-Gaussian fitting and survival analysis have been central in demonstrating the direct lexical control of fixation durations during reading (Reingold et al., 2012). Further studies using such techniques may reveal how lexical factors affect fixations in other tasks. Note that differences in the nature of lexical influences on eye movements may occur, not only due to the shorter time available during more rapid reading, but also due to reduced parafoveal processing. More rapid reading produces higher skipping rates and longer progressive saccades, which necessarily result in saccades being launched from more distant launch 
sites, therefore providing a more degraded parafoveal preview. During reading for comprehension, a substantial amount of lexical processing is undertaken based on the parafoveal preview and this "head start" effectively enables lexical factors to impact early in the subsequent fixation (Reingold et al., 2012; Reichle \& Reingold, 2013). More degraded parafoveal preview during rapid reading may result in more lexical processing occurring later.

We can further assess lexical influences on eye movement control by examining word skipping rates. There was no indication that word frequency (with orthographic familiarity controlled) affected word skipping during scanning. However orthographically unfamiliar infrequent words were skipped more often than frequent words for both reading and scanning, at least for saccades launched from the previous word. Therefore, at least for near launch sites, the mechanism underlying word targeting during scanning involves parafoveal processing at least at the level of orthography. Critically, such effects indicate that word targeting during topic scanning is not explained by a straightforward visual or oculomotor strategy (e.g. Just \& Carpenter, 1987; O’Regan, 1990).

The E-Z Reader model explains word skipping by completion of the first stage of word recognition $\left(\mathrm{L}_{1}\right)$ for parafoveal words. The model may account for higher skipping rates during topic scanning by an increased rate of lexical processing. However another possibility is that scanning entails a riskier saccade targeting strategy, such that skipped words are not always processed to the same lexical level as when reading for comprehension. Further research is required to examine in more detail factors that determine word skipping for topic scanning, as well as the nature of parafoveal preview. In the section below we consider how levels of understanding may differ in scanning compared to reading for comprehension. The possibility that a smaller proportion of words may be fully recognised during topic scanning is a key factor in determining the levels of comprehension that might be achieved. 
Later sentence processing (re-reading): Implications for eye movement control and comprehension

The present study showed clear effects of reading strategy on late measures of sentence processing. Late effects could reflect continued processing of words and their integration with sentence context (Levy, Bicknell, Slattery, \& Rayner, 2009). The global analyses showed longer rereading times during reading for comprehension than topic scanning, hence processes related to higher level sentence processing may occur to a lesser extent for topic scanning. Furthermore, only later measures of processing for the critical word (total time, regressions in) showed an interaction between task and target type. The smaller effects of word frequency in these measures for topic scanning than reading for comprehension are consistent with less integration of words into context during topic scanning. Interestingly, the different patterns of results (additive vs. interactive) for firstpass and later measures indicates that task impacts differentially on sub-components of word processing (also suggested by Schotter et al., 2014, in relation to proof-reading). It remains to be determined if other types of rapid reading, such as skimming for gist, also show reduced effects of linguistic variables on re-reading. However the indication from the present research is that the nature of the reading task modulates the degree to which word frequency affects the late processing of words, even when early measures of word processing are unaffected.

Just and Carpenter (1987) suggested skim reading involves reduced checks for syntactic and semantic consistency and this also might apply to topic scanning. That is, parameters linked to syntactic processing, such as those proposed by Engelmann, Vasishth, Engbert and Kliegl (2013), may be modulated by task. Sanford and Sturt (2002) noted that comprehension often is based on underspecified representations of text in which ambiguities or anomalies are not fully resolved. Hence it seems likely that text representations are underspecified during scanning. In E-Z Reader (Reichle, Warren et al., 2009) such processes are incorporated into the "I" parameter, representing post-lexical integration, which is the time needed to integrate a word into higher level syntactic and semantic representations. The time required for I, or the probability of integration failure, may be 
greater during careful reading than topic scanning. Such differences in post-lexical integration may explain differences in re-reading times, effects of word frequency on later measures, as well as differences in $\tau$ for the distribution of single first-pass fixation durations. Such differences may also reflect more superficial processing of irrelevant text (Kaakinen \& Hyönä, 2008)

The suggestion that higher level sentence integration processes differ for reading and topic scanning also may be couched in terms of Kintsch's (1998) construction-integration model of text comprehension. Kintsch suggested that text is first constructed in a bottom-up manner, with top down factors such as reading goals and perspective affecting a subsequent integration phase. Reading and topic scanning may be similar in the construction phase, with limited integration occurring for scanning of irrelevant text in the subsequent phase. Similar to skimming (Just \& Carpenter, 1987), scanning may not involve accurate recognition of all words in the text. Therefore the "construction" phase in Kintsch's model may be sparser during topic scanning compared to reading for comprehension, due to lower "standards of coherence" (van den Broek et al., 1995, 2001) for scanning. Topic scanning may require inferences to be made from only a subset of words to extract the macrostructure of the text (Kintsch \& van Dijk, 1978) and this may be sufficient to judge whether text is relevant to the topic. In contrast, reading for comprehension may necessitate higher standards of coherence, with more focus on the microstructure of text, resulting in longer re-reading times and larger effects of word frequency on later processing measures.

\section{Summary and future directions}

The key findings of this study are: (1) all/most first-pass fixations can be modulated by reading task, shown by the shift in the distribution of single fixation durations for scanning compared to reading; (2) early word recognition processes for fixated words are similar for reading for comprehension and scanning, shown by additive effects of task and word frequency for mean firstpass reading times; (3) later processes, perhaps related to integration of words into higher level 
representations, can vary with task, shown by longer re-reading times and a larger effect of word frequency on later measures during reading for comprehension compared to scanning. Crucially, the article has also highlighted the scope for exploring how models of reading might account for different reading strategies by adjusting parameters or thresholds for oculomotor control, or saccade programming triggers linked to lexical processing or text integration. Such an approach has the capacity to reveal more precisely the role of cognitive flexibility in eye movement control and word recognition systems, as well as possible flexibility in the co-ordination of these very different systems. Importantly, elucidating the nature of the mechanisms involved across different reading strategies requires further empirical work. For example, to examine the balance of linguistic and visual / oculomotor influences on eye movement control, the influence of task on the reader's perceptual span, and the role of higher-level linguistic influences. Reading strategies may vary across individuals (Hyönä, Lorch, \& Kaakinen, 2002), and interactions between task and linguistic variables also may vary with age (Wotschack \& Kliegl, 2013). Further research that addresses these issues will more fully reveal the nature of the mechanisms underlying flexibility in reading behaviour, which is surely central to the skill of reading. 


\section{References}

Baayen, R. H., Piepenbrock, R., \& Gulikers, L. (1995). The CELEX Lexical Database. [CD-ROM]. Philadelphia: Linguistic Data Consortium, University of Pennsylvania.

Balota, D. A., \& Yap, M. J. (2011). Moving beyond the mean in studies of mental chronometry the power of response time distributional analyses. Current Directions in Psychological Science, 20, 160-166. http://dx.doi.org/10.1177/0963721411408885

Balota, D. A., Yap, M. J., Cortese, M. J., Hutchison, K. A., Kessler, B., Loftis, B., et al. (2007). The English Lexicon Project. Behavior Research Methods, 39, 445-459. http://dx.doi.org/10.3758/BF03193014

Bicknell, K., \& Levy, R. (2010). A rational model of eye movement control in reading. Proceedings of the 48th Annual Meeting of the Association for Computational Linguistics, Cousineau, D., Brown, S., \& Heathcote, A. (2004). Fitting distributions using maximum likelihood: Methods and packages. Behavior Research Methods, Instruments, \& Computers, 36, $742-$ 756. http://dx.doi.org/10.3758/BF03206555

Dampuré, J., Ros, C., Rouet, J-F., \& Vibert, N. (2012). How word familiarity facilitates visual search for verbal material. Applied Cognitive Psychology, 26, 271-288. http://dx.doi.org/10.1002/acp.1821

Duggan, G.B., \& Payne, S.J. (2009). Text skimming: The process and effectiveness of foraging through text under time pressure. Journal of Experimental Psychology: Applied, 15, 228-242. http://dx.doi.org/10.1037/a0016995

Engbert, R., Longtin, A., \& Kliegl, R. (2002). A dynamical model of saccade generation in reading based on spatially distributed lexical processing. Vision Research, 42, 621-636. http://dx.doi.org/10.1016/S0042-6989(01)00301-7

Engbert, R., Nuthmann, A., Richter, E.M., \& Kliegl, R. (2005). SWIFT: A dynamical model of saccade generation during reading. Psychological Review, 112, 777-813. 
http://dx.doi.org/ 10.1037/0033-295X.112.4.777

Engelmann, F., Vasishth, S., Engbert, R., \& Kliegl, R. (2013). A framework for modeling the interaction of syntactic processing and eye movement control. Topics in Cognitive Science, 5, 452-474. http://dx.doi.org/10.1111/tops. 12026

Ferris, F.L., \& Bailey, I.L. (1996). Standardizing the measurement of visual acuity for clinical research studies. Ophthalmology, 103, 181-182. http://dx.doi.org/10.1016/S0161-6420(96)30742-2

Forster, K.I., \& Chambers, S.M. (1973). Lexical access and naming time. Journal of Verbal Learning and Verbal Behavior, 12, 627-635. http://dx.doi.org/10.1016/S0022-5371(73)80042-8

Heathcote, A., Brown, S., \& Mewhort, D. J. K. (2002). Quantile maximum likelihood estimation of response time distributions. Psychonomic Bulletin \& Review, 9, 394-401. http://dx.doi.org/10.3758/BF03196299

Henderson, J.M., \& Ferreira, F. (1990). Effects of foveal processing difficulty on the perceptual span in reading: Implications for attention and eye movement control. Journal of Experimental Psychology: Learning, Memory and Cognition, 16, 417-429. http://dx.doi.org/10.1037/0278-7393.16.3.417

Hyönä, J., Lorch, R.F. Jr, \& Kaakinen, J.K. (2002). Individual differences in reading to summarize expository text: Evidence from eye fixation patterns. Journal of Educational Psychology, 94, 44-55. http://dx.doi.org/10.1037/0022-0663.94.1.44

Inhoff, A.W., \& Rayner, K. (1986). Parafoveal word processing during eye fixations in reading: Effects of word frequency. Perception \& Psychophysics, 40, 431-439. http://dx.doi.org/10.3758/BF03208203

Just, M.A., \& Carpenter, P.A. (1987). Speed reading. In M.A. Just \& P.A. Carpenter (Eds.), The 
psychology of reading and language processing (pp. 425-452). Newton, MA: Allyn and Bacon.

Kaakinen, J.K., \& Hyönä, J. (2007). Perspective effects in repeated reading: An eye movement study. Memory \& Cognition, 35, 1323-1336. http://dx.doi.org/10.3758/BF03193604

Kaakinen, J.K., \& Hyönä, J. (2008). Perspective-driven text comprehension. Applied Cognitive Psychology, 22, 319-334. http://dx.doi.org/10.1002/acp.1412

Kaakinen, J.K., \& Hyönä, J. (2010). Task effects on eye movements during reading. Journal of Experimental Psychology: Learning, Memory, and Cognition, 36, 1561-1566. http://dx.doi.org/10.1037/a0020693

Kaakinen, J.K., \& Hyönä, J. (2014). Task relevance induces momentary changes in the functional visual field during reading. Psychological Science, 25, 626-632. http://dx.doi.org/10.1177/0956797613512332

Kaakinen, J.K., Hyönä, J., \& Keenan, J.M. (2002). Perspective effects on online text processing. Discourse Processes, 33, 159-173. http://dx.doi.org/10.1207/S15326950DP3302_03

Kennedy, A. (2000). Parafoveal processing in word recognition. Quarterly Journal of Experimental Psychology, 53A, 429-455. http://dx.doi.org/10.1080/713755901

Kintsch, W. (1998). Comprehension: A paradigm for cognition. Cambridge: Cambridge University Press.

Kintsch, W., \& van Dijk, T.A. (1978). Toward a model of text comprehension and production. Psychological Review, 85, 363-394. http://dx.doi.org/10.1037/0033-295X.85.5.363

Kuperman, V., Dambacher, M., Nuthmann, A., \& Kliegl, R. (2010). The effect of word position on eye-movements in sentence reading and paragraph reading. Quarterly Journal of Experimental Psychology, 63, 1838-1857. http://dx.doi.org/10.1080/17470211003602412

Kuperman, V., Drieghe, D., Keuleers, E., \& Brysbaert, M. (2013). How strongly do word reading 
times and lexical decision times correlate? Combining data from eye movement corpora and megastudies. Quarterly Journal of Experimental Psychology, 66, 563-580.

http://dx.doi.org/10.1080/17470218.2012.658820

Laycock, F. (1955). Significant characteristics of college students with varying flexibility in reading rate: I. Eye-movements in reading prose. Journal of Experimental Education, 23, 311-319.

Levy, R., Bicknell, K., Slattery, T., \& Rayner, K. (2009). Eye movement evidence that readers maintain and act on uncertainty about past linguistic input. Proceedings of the National Academy of Sciences, 106, 21086-21090. http://dx.doi.org/10.1073/pnas.0907664106

Lewis, R., Shvartsman, M., \& Singh, S. (2013). The adaptive nature of eye-movements in linguistic tasks: How payoff and architecture shape speed-accuracy trade-offs. Topics in Cognitive Science, 5, 581-610. http://dx.doi.org/10.1111/tops.12032

Luke, S.G., \& Henderson, J.M. (2013). Oculomotor and cognitive control of eye movements in reading: Evidence from mindless reading. Attention, Perception, \& Psychophysics, 75, 12301242. http://dx.doi.org/10.3758/s13414-013-0482-5

Lund, K., \& Burgess, C. (1996). Producing high-dimensional semantic spaces from lexical cooccurrence. Behavior Research Methods, Instruments, \& Computers, 28, 203-208. http://dx.doi.org/10.3758/BF03204766

Masson, M.E.J. (1982). Cognitive processes in skimming stories. Journal of Experimental Psychology: Learning, Memory, and Cognition, 8, 400-417. http://dx.doi.org/10.1037/0278-7393.8.5.400

Masson, M.E.J. (1983). Conceptual processing of text during skimming and rapid sequential reading. Memory \& Cognition, 11, 262-274. http://dx.doi.org/10.3758/BF03196973

Matzke, D., \& Wagenmakers, E.-J. (2009). Psychological interpretation of the ex-Gaussian and shifted Wald parameters: A diffusion model analysis. Psychonomic Bulletin \& Review, 16, 798 - 817. http://dx.doi.org/10.3758/PBR.16.5.798 
McConkie, G.W., Kerr, P.W., Reddix, M.D., \& Zola, D. (1988). Eye movement control during reading: I. The location of initial eye fixations on words. Vision Research, 28, 1107-1118. http://dx.doi.org/10.1016/0042-6989(88)90137-X

McConkie, G.W., \& Rayner, K. (1974). Investigation of reading strategies: I. Manipulating strategies through payoff conditions. Journal of Literacy Research, 6, 9-18. http://dx.doi.org/ 10.1080/10862967409547072

McConkie, G.W., Rayner, K., \& Wilson, S.J. (1973). Experimental manipulation of reading strategies. Journal of Educational Psychology, 65, 1-8. http://dx.doi.org/10.1037/h0034822

Murray, W.S., \& Forster, K.I. (2008). The rank hypothesis and lexical decision: A reply to Adelman and Brown (2008). Psychological Review, 115, 240-252. http://dx.doi.org/10.1037/0033-295X.115.1.240

Neely, J.H. (1977). Semantic priming and retrieval from lexical memory: Roles of inhibitionless spreading activation and limited-capacity attention. Journal of Experimental Psychology: General, 106, 226-254. http://dx.doi.org/10.1037/0096-3445.106.3.226

O'Regan, J. K. (1990). Eye movements and reading. In E. Kowler (Ed.), Eye movements and their role in visual and cognitive processes (pp. 395-453). Amsterdam: Elsevier.

Pichert, J.W., \& Anderson, R.C. (1977). Taking different perspectives on a story. Journal of Educational Psychology, 69, 309-315. http://dx.doi.org/10.1037/0022-0663.69.4.309

Radach, R., Huestegge, L., \& Reilly, R. (2008). The role of global top-down factors in local eyemovement control in reading. Psychological Research, 72, 675-688. http://dx.doi.org/10.1007/s00426-008-0173-3

Ratcliff, R. (1979). Group reaction time distributions and an analysis of distribution statistics. Psychological Bulletin, 86, 446-461. http://dx.doi.org/10.1037/0033-2909.86.3.446 Rayner, K. (2009). Eye movements and attention in reading, scene perception, and visual search. Quarterly Journal of Experimental Psychology, 62, 1457-1506. 
http://dx.doi.org/ 10.1080/17470210902816461

Rayner, K., \& Duffy, S.A. (1986). Lexical complexity and fixation times in reading: Effects of word frequency, verb complexity and lexical ambiguity. Memory \& Cognition, 14, 191-201. http://dx.doi.org/10.3758/BF03197692

Rayner, K., \& Fischer, M.H. (1996). Mindless reading revisited: Eye movements during reading and scanning are different. Perception \& Psychophysics, 58, 734-747. http://dx.doi.org/10.3758/BF03213106

Rayner, K., Liversedge, S.P., White, S.J., \& Vergilino-Perez, D. (2003). Reading disappearing text: Cognitive control of eye movements. Psychological Science, 14, 385-388. http://dx.doi.org/10.1111/1467-9280.24483

Rayner, K., \& Pollatsek, A. (1987). Eye movements in reading: A tutorial review. In: M. Coltheart (Ed.), Attention and performance (Vol. 12, pp. 327-362). London, UK: Erlbaum.

Rayner, K., \& Raney, G.E. (1996). Eye movement control in visual search: Effects of word frequency. Psychonomic Bulletin \& Review, 3, 245-248. http://dx.doi.org/10.3758/BF03212426

Rayner, K., Sereno, S.C., \& Raney, G.E. (1996). Eye movement control in reading: A comparison of two types of models. Journal of Experimental Psychology: Human Perception and Performance, 22, 1188-1200. http://dx.doi.org/10.1037/0096-1523.22.5.1188

Reichle, E.D., Liversedge, S.P., Pollatsek, A., \& Rayner, K. (2009). Encoding multiple words simultaneously in reading is implausible. Trends in Cognitive Science, 13, 115-119. http://dx.doi.org/10.1016/j.tics.2008.12.002

Reichle, E. D., Pollatsek, A., Fisher, D. L., \& Rayner, K. (1998). Toward a model of eye movement control in reading. Psychological Review, 105, 125-157. http://dx.doi.org/10.1037/0033-295X.105.1.125

Reichle, E.D., Rayner, K., \& Pollatsek, A. (2003). The E-Z Reader model of eye movement control 
in reading: Comparisons to other models. Behavioral and Brain Sciences, 26, 445-526. http://dx.doi.org/10.1017/S0140525X03000104

Reichle, E.D., Reineberg, A.E., \& Schooler, J.W. (2010). Eye movements during mindless reading. Psychological Science, 21, 1300-1310. http://dx.doi.org/10.1177/0956797610378686

Reichle, E.D., \& Reingold, E.M. (2013). Neurophysiological constraints on the eye-mind link. Frontiers in Human Neuroscience, 7, 361. http://dx.doi.org/10.3389/fnhum.2013.00361

Reichle, E.D., Warren, T., \& McConnell, K. (2009). Using E-Z Reader to model the effects of higher level language processing on eye movements during reading. Psychonomic Bulletin \& Review, 16, 1-21. http://dx.doi.org/10.3758/PBR.16.1.1

Reilly, R.G., \& Radach, R. (2006). Some empirical tests of an interactive activation model of eye movement control in reading. Cognitive Systems Research, 7, 34-55. http://dx.doi.org/10.1016/j.cogsys.2005.07.006

Reingold, E.M., Reichle, E.D., Glaholt, M.G., \& Sheridan, H. (2012). Direct lexical control of eye movements in reading: Evidence from a survival analysis of fixation durations. Cognitive Psychology, 65, 177-206. http://dx.doi.org/10.1016/j.cogpsych.2012.03.001

Sanford., A.J., \& Sturt, P. (2002). Depth of processing in language comprehension: not noticing the evidence. Trends in Cognitive Sciences, 6, 382-386. http://dx.doi.org/10.1016/S1364-6613(02)01958-7

Schad, D.J., Nuthmann, A., \& Engbert, R. (2012). Your mind wanders weakly, your mind wanders deeply: Objective measures reveal mindless reading at different levels. Cognition, 125, 179194. http://dx.doi.org/10.1016/j.cognition.2012.07.004

Schilling, H.E.H., Rayner, K., \& Chumbley, J.I. (1998). Comparing naming, lexical decision, and eye fixation times: Word frequency effects and individual differences. Memory \& Cognition, 26, 1270-1281. http://dx.doi.org/10.3758/BF03201199

Schotter, E.R., Bicknell, K., Howard, I., Levy, R., \& Rayner, K. (2014). Task effects reveal 
cognitive flexibility responding to frequency and predictability: Evidence from eye movements in reading and proofreading. Cognition, 131, 1-27.

http://dx.doi.org/10.1016/j.cognition.2013.11.018

Schroyens, W., Vitu, F., Brysbaert, M., \& d'Ydewalle, G. (1999). Eye movement control during reading: Foveal load and parafoveal processing. Quarterly Journal of Experimental Psychology, 52A, 1021-1046. http://dx.doi.org/10.1080/027249899390909

Sheridan, H., \& Reingold, E.M. (2012a). The time course of contextual influences during lexical ambiguity resolution: Evidence from distributional analyses of fixation durations. Memory \& Cognition, 40, 1122-1131. http://dx.doi.org/10.3758/s13421-012-0216-2

Sheridan, H., \& Reingold, E.M. (2012b). The time course of predictability effects in reading: Evidence from a survival analysis of fixation durations. Visual Cognition, 20, 733-745. http://dx.doi.org/10.1080/13506285.2012.693548

Simola, J., Salojärvi, J., \& Kojo, I. (2008). Using hidden Markov model to uncover processing states from eye movements in information search tasks. Cognitive Systems Research, 9, 237-251. http://dx.doi.org/10.1016/j.cogsys.2008.01.002

Staub, A. (2011). The effect of lexical predictability on distributions of eye fixation durations. Psychonomic Bulletin \& Review, 18, 371-376. http://dx.doi.org/10.3758/s13423-010-0046-9

Staub, A., \& Benatar, A. (2013). Individual differences in fixation duration distributions in reading. Psychonomic Bulletin \& Review, 20, 1304-1311. http://dx.doi.org/10.3758/s13423-013-0444-x

Staub, A., \& Rayner, K. (2007). Eye movements and on-line comprehension processes. In: G. Gaskell (Ed.), The Oxford Handbook of Psycholinguistics (pp. 327-342). Oxford, UK: Oxford University Press.

Staub, A., White, S.J., Drieghe, D., Hollway, E.C., \& Rayner, K. (2010). Distributional effects of 
word frequency on eye fixation durations. Journal of Experimental Psychology: Human Perception and Performance, 36, 1280-1293. http://dx.doi.org/10.1037/a0016896

van den Broek, P., Lorch, R.F., Linderholm, T., \& Gustafson, M. (2001). The effects of readers' goals on inference generation and memory for texts. Memory \& Cognition, 29, 1081-1087. http://dx.doi.org/10.3758/BF03206376

van den Broek, P., Risden, K., \& Husebye-Hartmann, E. (1995). The role of readers' standards for coherence in the generation of inferences during reading. In R. F. Lorch, Jr, \& E. J. O’Brien (Eds.), Sources of coherence in text comprehension (pp. 353-373). Hillsdale, NJ: Erlbaum.

van Heuven, W.J.B., Mandera, P., Keuleers, E., \& Brysbaert, M. (2014). SUBTLEX-UK: A new and improved word frequency database for British English. Quarterly Journal of Experimental Psychology, 67, 1176-1190. http://dx.doi.org/10.1080/17470218.2013.850521

Van Zandt, T. (2000). How to fit a response time distribution. Psychonomic Bulletin \& Review, 7 , 424-465. http://dx.doi.org/10.3758/BF03214357

Vincent, S. B. (1912). The function of the viborissae in the behavior of the white rat. Animal Behavior Monographs, 1, (5).

Vitu, F., O’Regan, J.K., Inhoff, A.W., \& Topolski, R. (1995). Mindless reading: Eye movement characteristics are similar in scanning letter strings and reading texts. Perception \& Psychophysics, 57, 352-364. http://dx.doi.org/10.3758/BF03213060

White, S. J. (2008). Eye movement control during reading: Effects of word frequency and orthographic familiarity. Journal of Experimental Psychology: Human Perception and Performance, 34, 205-223. http://dx.doi.org/10.1037/0096-1523.34.1.205

White, S.J., \& Staub, A. (2012). The distribution of fixation durations during reading: Effects of stimulus quality. Journal of Experimental Psychology: Human Perception and Performance, 38, 603-617. http://dx.doi.org/10.1037/a0025338

Whitford, V., \& Titone, D. (2014). The effects of reading comprehension and launch site on 
frequency-predictability interactions during paragraph reading. Quarterly Journal of Experimental Psychology, 67, 1151-1165. http://dx.doi.org/10.1080/17470218.2013.848216

Wotschack, C., \& Kliegl, R. (2013). Reading strategy modulates parafoveal-on-foveal effects in sentence reading. Quarterly Journal of Experimental Psychology, 66, 548-562. http://dx.doi.org/10.1080/17470218.2011.625094

Yang, S.-N., \& McConkie, G. (2001). Eye movements during reading: A theory of saccade initiation times. Vision Research, 41, 3567-3585. http://dx.doi.org/10.1016/S0042-6989(01)00025-6 


\section{Footnotes}

${ }^{1}$ Subsequent to conducting the experiment, word frequencies were retrospectively calculated for the SUBTLEX-UK corpus (van Heuven, Mandera, Keuleers, \& Brysbaert, 2014) (downloaded from http://crr.ugent.be/archives/1423, 11/11/13). In line with the HAL corpus, Zipf word frequencies were significantly higher for the frequent compared to infrequent words. However in contrast to the HAL corpus, SUBTLEX-UK did show a small but significant difference in word frequency between the infrequent word conditions, with the infrequent orthographically unfamiliar words being less frequent $(M=3.12, S E=0.08)$ than the infrequent orthographically familiar words $(M=3.40, S E=0.07), t(70)=2.62, p<.05$. Therefore it is possible that any difference between the two infrequent word conditions could be due to the difference in orthographic familiarity, or due to a small but significant difference in word frequency as shown by the SUBTLEX-UK database, though not by the HAL database.

${ }^{2}$ The global pattern of longer progressive saccades during scanning compared to reading is consistent with analyses of saccade targeting for the critical word. Launch sites prior to fixating the critical word were further away and saccade lengths to the critical word were longer for scanning. Note that more distant launch sites have been shown to be associated with initial fixation positions nearer to the beginning of words (McConkie, Kerr, Reddix, \& Zola, 1988), which is also consistent with the finding that, for the experimental items, initial first-pass fixation positions were significantly nearer to the beginning of the critical word for scanning compared to reading. 
Acknowledgements

The research was supported by an Experimental Psychology Society Undergraduate Research Bursary. We thank Erik Reichle and an anonymous reviewer for their helpful comments on an earlier version of this manuscript. 
Table 1. Example Experimental Item in Each of the Three Target Word Conditions, The Critical Word is Indicated Here With Italics. Two Examples of Clothing Related Items.

\begin{tabular}{lll}
\hline Stimuli type & Condition & Example sentence \\
\hline Experimental & Frequent (orthographically familiar) & He loved to visit the local town near to where his grandparents lived. \\
& Infrequent orthographically familiar & He loved to visit the local cove near to where he learnt to swim. \\
& Infrequent orthographically unfamiliar & He loved to visit the local quay near to his father's fish shop. \\
\hline Clothing related & & He hated the boring socks he received as a Christmas gift. \\
& The dancer performed the lively tango and ripped the hem of her dress.
\end{tabular}


Table 2. Global Results for Reading and Topic Scanning: Mean Reading Measures and Mean Ex-Gaussian Parameter Values for Single Fixation Durations. Paired Sample $t$ Values are Shown for the Difference Between Reading and Topic Scanning for Each Measure.

\begin{tabular}{lcccc}
\hline Measure & Reading & Topic scanning & $t_{1}$ & $t_{2}$ \\
\hline First-pass summed reading time & $1909(90)$ & $1334(64)$ & $9.04 * * *$ & $34.10 * * *$ \\
Number of first-pass fixations & $7.85(0.31)$ & $5.98(0.28)$ & $9.73 * * *$ & $30.42 * * *$ \\
Re-reading time & $672(88)$ & $200(44)$ & $7.23 * * *$ & $24.45 * * *$ \\
Number of re-reading fixations & $2.82(0.41)$ & $1.03(0.23)$ & $6.62 * * *$ & $20.54 * * *$ \\
Average fixation duration & $244(6)$ & $220(5)$ & $8.48 * * *$ & $22.89 * * *$ \\
Progressive saccade length & $8.96(0.36)$ & $11.14(0.47)$ & $8.06 * * *$ & $23.13 * * *$ \\
\hline Ex-Gaussian parameter: $\mu$ & $163(4)$ & $155(5)$ & $3.08 * *$ & - \\
Ex-Gaussian parameter: $\sigma$ & $27(2)$ & $27(2)$ & $<1$ & - \\
Ex-Gaussian parameter: $\tau$ & $70(5)$ & $58(4)$ & $3.00 * *$ & -
\end{tabular}

Notes: Standard Errors are shown in parentheses. Degrees of freedom: $t_{1}(23), t_{2}(35)$.

$\dagger p<.10, * p<.05, * * p<.01, * * * p<.001$ 
Table 3. Global Results for Reading and Topic Comprehension: Mean Reading Measures. Paired Sample $t$ Values are Shown for the Difference Between Reading and Topic Comprehension for Each Measure.

\begin{tabular}{lcccc}
\hline Measure & Reading & Topic comprehension & $t_{1}$ & $t_{2}$ \\
\hline First-pass summed reading time & $1846(92)$ & $1483(69)$ & $6.92 * * *$ & $9.08 * * *$ \\
Number of first-pass fixations & $7.60(0.31)$ & $6.25(0.28)$ & $7.94 * * *$ & $6.88 * * *$ \\
Re-reading time & $652(88)$ & $556(106)$ & 1.03 & 1.59 \\
Number of re-reading fixations & $2.76(0.41)$ & $2.41(0.51)$ & 0.80 & 1.10 \\
Average fixation duration & $244(6)$ & $241(6)$ & 0.86 & 0.72 \\
Progressive saccade length & $9.06(0.34)$ & $10.84(0.47)$ & $6.52 * * *$ & $6.31 * * *$
\end{tabular}

Notes: Standard Errors are shown in parentheses. Degrees of freedom: $t_{1}(23), t_{2}(19)$.

$\dagger p<.10, * p<.05, * * p<.01, * * * p<.001$ 
Table 4. Local Results for Reading and Topic Scanning: Mean Reading Measures for the Critical Word for Each Target Type.

\begin{tabular}{lllcccc}
\hline Measure & Task & $\begin{array}{c}\text { Frequent, } \\
\text { orthographically } \\
\text { familiar }\end{array}$ & $\begin{array}{c}\text { Infrequent, } \\
\text { orthographically } \\
\text { familiar }\end{array}$ & $\begin{array}{c}\text { Frequency } \\
\text { effect }\end{array}$ & $\begin{array}{c}\text { Infrequent, } \\
\text { orthographically } \\
\text { unfamiliar }\end{array}$ & $\begin{array}{c}\text { Orthographic } \\
\text { familiarity } \\
\text { effect }\end{array}$ \\
\hline First fixation duration (ms) & Reading & $227(8)$ & $248(8)$ & 21 & $258(10)$ & 10 \\
& Scanning & $213(6)$ & $237(7)$ & 24 & $237(7)$ & 0 \\
\hline Gaze duration (ms) & Reading & $234(7)$ & $266(12)$ & 32 & $279(13)$ & 13 \\
& Scanning & $217(6)$ & $244(8)$ & 27 & $248(8)$ & 4 \\
\hline Total time (ms) & Reading & $273(9)$ & $342(21)$ & 69 & $350(20)$ & 8 \\
& Scanning & $227(8)$ & $267(11)$ & 40 & $254(10)$ & -13 \\
\hline Regressions out probability & Reading & $0.08(0.02)$ & $0.11(0.04)$ & 0.03 & $0.11(0.03)$ & 0 \\
& Scanning & $0.05(0.02)$ & $0.10(0.03)$ & 0.05 & $0.05(0.02)$ & -0.05 \\
\hline Regressions in probability & Reading & $0.12(0.02)$ & $0.25(0.03)$ & 0.13 & $0.21(0.02)$ & -0.04 \\
(all data) & Scanning & $0.08(0.02)$ & $0.14(0.02)$ & 0.06 & $0.18(0.02)$ & -0.04 \\
\hline Regressions in probability & Reading & $0.08(0.02)$ & $0.24(0.04)$ & 0.16 & $0.17(0.02)$ & -0.07 \\
(fixate word n on first-pass) & Scanning & $0.05(0.02)$ & $0.09(0.02)$ & 0.04 & $0.07(0.02)$ & -0.02 \\
\hline
\end{tabular}

Note. "word n" refers to the critical word. Standard Errors are shown in parentheses. 
Table 5. Local Results for Reading and Topic Scanning: Statistical Values for Analyses of Reading Measures for the Critical Word.

\begin{tabular}{|c|c|c|c|c|c|}
\hline \multirow[t]{2}{*}{ Measure } & & \multicolumn{2}{|c|}{$F_{1}$} & \multicolumn{2}{|c|}{$F_{2}$} \\
\hline & & $F$ & $\eta_{\mathrm{p}}^{2}$ & $F$ & $\eta_{\mathrm{p}}^{2}$ \\
\hline \multirow{3}{*}{$\begin{array}{l}\text { First fixation } \\
\text { duration }\end{array}$} & Task & $7.90 *$ & 0.26 & $14.88 * * *$ & 0.30 \\
\hline & Target type & $30.24 * * *$ & 0.57 & $19.65 * * *$ & 0.36 \\
\hline & Task X Target type & 0.66 & 0.03 & 0.62 & 0.02 \\
\hline \multirow[t]{3}{*}{ Gaze duration } & Task & $9.11 * *$ & 0.28 & $25.82 * * *$ & 0.42 \\
\hline & Target type & $31.55 * * *$ & 0.58 & $25.65 * * *$ & 0.42 \\
\hline & Task X Target type & 1.33 & 0.06 & 2.05 & 0.06 \\
\hline \multirow[t]{3}{*}{ Total time } & Task & $37.92 * * *$ & 0.62 & $96.68 * * *$ & 0.73 \\
\hline & Target type & $19.61 * * *$ & 0.46 & $30.8 * * *$ & 0.47 \\
\hline & Task X Target type & $5.18 * *$ & 0.18 & $3.89 *$ & 0.10 \\
\hline Regressions & Task & 2.56 & 0.10 & $3.52 \dagger$ & 0.09 \\
\hline \multirow[t]{2}{*}{ out } & Target type & $3.05 \dagger$ & 0.12 & $4.16 *$ & 0.11 \\
\hline & Task X Target type & 1.05 & 0.04 & 0.96 & 0.03 \\
\hline Regressions & Task & $8.00 *$ & 0.26 & $13.98 * *$ & 0.29 \\
\hline \multirow[t]{2}{*}{ in, all data } & Target type & $14.89 * * *$ & 0.39 & $12.31 * * *$ & 0.26 \\
\hline & Task X Target type & $2.74 \dagger$ & 0.11 & $2.50 \dagger$ & 0.07 \\
\hline Regressions & Task & $27.46 * * *$ & 0.54 & $33.16 * * *$ & 0.49 \\
\hline \multirow[t]{2}{*}{ in, fix wd n } & Target type & $14.24 * * *$ & 0.38 & $8.50 * *$ & 0.20 \\
\hline & Task X Target type & $4.02 *$ & 0.15 & $3.00 \dagger$ & 0.08 \\
\hline
\end{tabular}

Notes: "fix wd n" indicates that the analysis is restricted to trials for which the critical word was fixated on first-pass. Degrees of freedom: Task: $F_{1}(1,23), F_{2}(1,35)$; Target type:

$F_{1}(2,46), F_{2}(2,70)$; Task X Target type: $F_{1}(2,46), F_{2}(2,70)$.

$\dagger p<.10, * p<.05, * * p<.01, * * * p<.001$ 
Table 6. Local Results for Reading and Topic Scanning: Mean Measures for Word Skipping and Fixations Before / After the Critical Word.

\begin{tabular}{lllcccc}
\hline Measure & Task & $\begin{array}{c}\text { Frequent, } \\
\text { orthographically } \\
\text { familiar }\end{array}$ & $\begin{array}{c}\text { Infrequent, } \\
\text { orthographically } \\
\text { familiar }\end{array}$ & $\begin{array}{c}\text { Frequency } \\
\text { effect }\end{array}$ & $\begin{array}{c}\text { Infrequent, } \\
\text { orthographically } \\
\text { unfamiliar }\end{array}$ & $\begin{array}{c}\text { Orthographic } \\
\text { familiarity } \\
\text { effect }\end{array}$ \\
\hline Skip probability (all data) & Reading & $0.27(0.04)$ & $0.25(0.04)$ & 0.02 & $0.20(0.03)$ & 0.05 \\
& Scanning & $0.41(0.04)$ & $0.44(0.04)$ & -0.03 & $0.39(0.03)$ & 0.05 \\
\hline Skip probability (fixate n-1) & Reading & $0.37(0.05)$ & $0.33(0.06)$ & 0.04 & $0.26(0.05)$ & 0.07 \\
& Scanning & $0.61(0.06)$ & $0.62(0.06)$ & -0.01 & $0.56(.06)$ & 0.06 \\
\hline Fixation duration before & Reading & $213(8)$ & $213(8)$ & 0 & $214(7)$ & 1 \\
fixating word n (ms) & Scanning & $194(7)$ & $192(8)$ & -2 & $197(8)$ & 5 \\
\hline Gaze duration for word n-1 & Reading & $234(8)$ & $236(9)$ & 2 & $236(10)$ & 0 \\
(ms) & Scanning & $217(8)$ & $213(8)$ & -4 & $212(6)$ & -1 \\
\hline Fixation duration after & Reading & $220(7)$ & $231(8)$ & 11 & $230(10)$ & -1 \\
leaving word $\mathrm{n}$ (ms) & Scanning & $209(8)$ & $215(8)$ & 6 & $217(7)$ & 2 \\
\hline
\end{tabular}

Note. Standard Errors are shown in parentheses. "word n" refers to the critical word and "word n-1" refers to the word before the critical word. "Skip probability" refers to the proportion of cases where the critical word was skipped on first-pass. The analysis "Skip probability (fixate n-1)" is restricted to cases where the word prior to the critical word was fixated on first-pass. 
Table 7. Local Results for Reading and Topic Scanning: Statistical Values for Word Skipping and Fixations Before / After the Critical Word.

\begin{tabular}{llcccc}
\hline Measure & & \multicolumn{2}{c}{$F_{1}$} & \multicolumn{2}{c}{$F_{2}$} \\
\cline { 3 - 5 } Skip probability & Task & $F$ & $\eta_{\mathrm{p}}{ }^{2}$ & $\eta_{\mathrm{p}}{ }^{2}$ \\
& Target type & $27.06 * * *$ & 0.54 & $78.12 * * *$ & 0.69 \\
& Task X Target type & 1.2 & 0.05 & 0.83 & 0.02 \\
\hline Skip probability & Task & $50.19 * * *$ & 0.69 & $122.08 * * *$ & 0.78 \\
(fixate n-1) & Target type & $6.52 * *$ & 0.22 & $5.87 * *$ & 0.14 \\
& Task X Target type & 0.72 & 0.03 & 0.88 & 0.02 \\
\hline Fixation duration & Task & $14.37 * *$ & 0.39 & $68.31 * * *$ & 0.66 \\
before fixating & Target type & 0.63 & 0.03 & 0.46 & 0.01 \\
word n & Task X Target type & 0.29 & 0.01 & 0.79 & 0.02 \\
\hline Gaze duration for & Task & $12.84 * *$ & 0.36 & $41.55 * * *$ & 0.54 \\
word n-1 & Target type & 0.13 & 0.01 & 0.44 & 0.01 \\
& Task X Target type & 0.82 & 0.04 & 0.34 & 0.01 \\
\hline Fixation duration & Task & $11.55 * *$ & 0.33 & $21.5 * * *$ & 0.38 \\
after leaving & Target type & 2.33 & 0.09 & 1.17 & 0.03 \\
word n & Task X Target type & 0.32 & 0.01 & 0.71 & 0.02 \\
\hline Notes: See note for Tab & & & &
\end{tabular}

Notes: See note for Table 6 for abbreviated terms.

Degrees of freedom: Task: $F_{1}(1,23), F_{2}(1,35)$; Target type: $F_{1}(2,46), F_{2}(2,70)$; Task X Target type: $F_{1}(2,46), F_{2}(2,70)$.

$\dagger p<.10, * p<.05, * * p<.01, * * * p<.001$ 
Figure caption

Vincentile plot for observed single first-pass fixation durations on words four to seven letters long for the reading and topic scanning conditions (excluding fixations on the first and last words within each sentence). Error bars show the standard error of the mean. Predicted vincentiles are shown by triangles and are based on the mean ex-Gaussian parameters. 
Figure

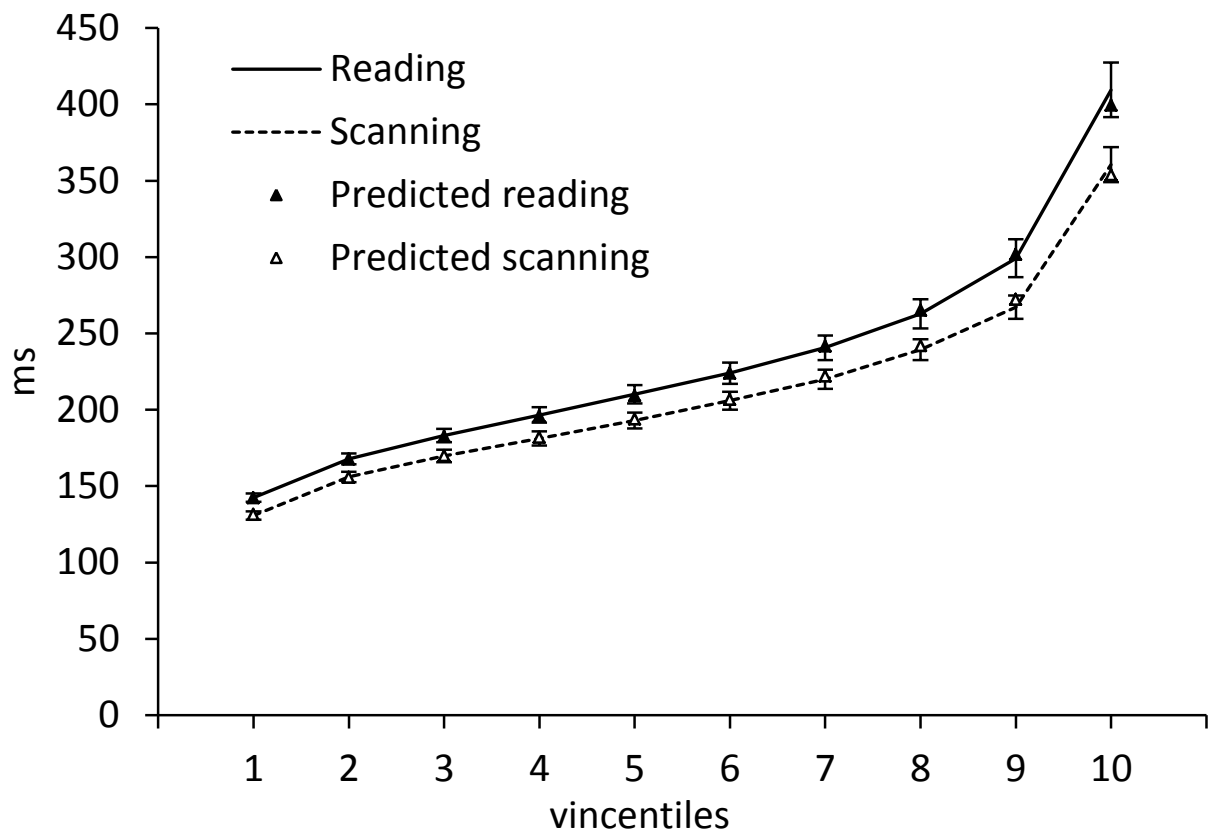

